\title{
Transport of Sodium and Urea in Outer Medullary Descending Vasa Recta
}

Thomas L. Pallone, Jack Work, Roland L. Myers, and Rex L. Jamison

Division of Nephrology and Department of Anatomy, The M.S. Hershey Medical Center, Pennsylvania

State University, Hershey, Pennsylvania 17033; Divisions of Nephrology, The Louisiana State

University, Shreveport, Louisiana 71130; and Stanford University, Stanford, California 94305

\section{Abstract}

We dissected and perfused outer medullary vasa recta (OMVR) from vascular bundles in the rat. Permeabilities of sodium $\left(P_{\mathrm{Na}}\right)$ and urea $\left(P_{\mathrm{u}}\right)$ were simultaneously determined from the lumen-to-bath efflux of ${ }^{22} \mathrm{Na}$ and $\left[{ }^{14} \mathrm{C}\right]$ urea. $P_{\mathrm{Na}}$ and $P_{\mathrm{u}}$ were also measured by in vivo microperfusion of descending (DVR) and ascending vasa recta (AVR) at the papillary tip of Munich-Wistar rats. In some OMVR $P_{\mathrm{Na}}$ was indistinguishable from zero. The mean \pm SE of $P_{\mathrm{Na}}\left(\times 10^{-5}, \mathrm{~cm} / \mathrm{s}\right)$ in OMVR was 76 $99 . P_{u}$ in OMVR was always very high $\left(\times 10^{-5}, \mathrm{~cm} / \mathrm{s}\right)$, $360 \pm 14$. There was no correlation between $O M V R P_{N a}$ and $P_{u}$. Inner medullary AVR and DVR had $P_{\mathrm{Na}}$ of $115 \pm 10$ and $75 \pm 10$, respectively, and $P_{u}$ of $121 \pm 10$ and $76 \pm 11$, respectively. $P_{\mathrm{Na}}$ and $P_{u}$ in papillary vasa recta were always nearly identical and highly correlated. Transport of $\left[{ }^{14} \mathrm{C}\right]$ urea in OMVR was reversibly inhibited by addition of unlabeled urea or phloretin to the bath and lumen, providing evidence for carrier-mediated transport. These data suggest that sodium and urea might traverse the wall of inner medullary vasa recta by a paracellular pathway while urea also crosses by a transcellular route in OMVR. Electron microscopic examination of seven in vitro perfused OMVR revealed no fenestrations and exposure of these vessels to $10 \mu \mathrm{M}$ calcium ionophore $\mathrm{A23187}$ or $1 \mathrm{nM}$ angiotensin II resulted in reversible contraction, suggesting that in vitro perfused OMVR are DVR only. (J. Clin. Invest. 1994. 93:212222.) Key words: angiotensin - microcirculation • microperfusion $\bullet$ rat $\bullet$ urinary concentration

\section{Introduction}

It is generally accepted that the microcirculation of the renal medulla has evolved to subserve two opposing roles. In common with the capillaries that perfuse other organs, vasa recta supply oxygen and nutrients required for cellular processes. The renal medulla, however, has the unique requirement that this must be accomplished without dissipation of the corticomedullary gradients of sodium and urea generated by the loops of Henle and collecting tubules (1), so that vasa recta function as countercurrent exchangers.

Perhaps the most striking feature of the medullary microcirculation in water conserving species is the incorporation of

Address correspondence to Dr. Thomas L. Pallone, Division of Nephrology, The Milton S. Hershey Medical Center, Pennsylvania State University, P.O. Box 850, Hershey, PA 17033.

Received for publication 19 February 1993 and in revised form 10 August 1993.

J. Clin. Invest.

(C) The American Society for Clinical Investigation, Inc. 0021-9738/94/01/0212/11 $\$ 2.00$

Volume 93, January 1994, 212-222 descending (DVR) ${ }^{1}$ and ascending (AVR) vasa recta into tightly packed vascular bundles in the inner stripe of the outer medulla (2-5). Efferent arterioles arising from juxtamedullary glomeruli give rise to DVR, all of which reach their destinations by way of vascular bundles. DVR on the periphery of the bundles peel off to supply the dense capillary plexus of the outer medullary interbundle region whereas centrally located DVR transverse the axis of the bundles to supply blood flow to the inner medulla. All AVR arising from the inner medulla enter the vascular bundles to reach the cortex. In contrast, AVR from the plexus in the outer medullary interbundle region reach the cortex without joining the vascular bundles (6). In many species, descending thin limbs of short looped nephrons migrate to the periphery of the bundles or become incorporated within the bundle region (2-6). Taken together it seems apparent that the anatomical arrangement serves a vital role $(s)$ in the renal medullary handling of solutes and water.

The purpose of the vascular bundles is not entirely understood. The radial separation of DVR supplying the inner and outer medulla coupled with the existence of innervation and contractile elements (pericytes) in the wall of some DVR has suggested to several authors that vascular bundles may be a site for the regulation of the regional distribution of medullary blood flow, an issue which has been the topic of extensive investigation (see reviews in references 5 and 7). It seems apparent that the anatomical arrangement of the bundles also enables highly efficient countercurrent exchange and trapping of concentrated solute returning in AVR from the inner medulla. The latter function would be best served by high permeability of DVR and AVR to sodium and urea.

To date, only the transport properties of inner medullary vasa recta have been examined by microperfusion methods in vivo (8-11). Owing to the poor accessibility of the inner medulla in vivo, such studies are limited to vasa recta on the papillary surface at the distal third of the inner medulla. In the present study, we have employed the in vitro microperfusion method of Burg et al. $(12,13)$ and a dual-isotope method to examine simultaneous unidirectional lumen-to-bath isotopic sodium and urea efflux in vasa recta dissected from the outer medullary vascular bundles in the rat. The results show a uniform, extremely high permeability to urea. In contrast, many of the same vessels have a low permeability to sodium. This finding suggests that outer medullary vascular bundles are responsible for selectively distributing solute recovered from nephron segments in the inner medulla.

1. Abbreviations used in this paper: AVR, ascending vasa recta; DVR, descending vasa recta; FITC-Dx, FITC-labeled dextran; LDLu, upper, outer medullary portion of the thin descending limb of long-looped nephron; OMVR, outer medullary vasa recta; $P D$, potential difference; SDL, thin descending limb of short-looped nephron; TALH and tALH, think and thin ascending limb of Henle's loop; TEM, transmission electron microscopy. 


\section{Methods}

\section{Microperfusion studies}

In vitro. The method used to perfuse outer medullary vasa recta (OMVR) is a minor modification of that described by Burg et al. (12, 13). The apparatus used includes an inverted microscope (Diaphot; Nikon Inc., Melville, NY) equipped with differential interference contrast (Nomarski) optics. The Micromanipulators, perfusion and collection apparatus, and perfusion chamber were purchased from Instruments Technology and Machinery (ITM, San Antonio, TX) or White Instruments (Bethesda, MD). Temperature of the perfusion chamber was maintained at $37^{\circ} \mathrm{C}$ by a feedback system employing a model CN9111A controller (Omega Engineering, Inc., Stamford, CT) and a thermistor probe placed in the center of the perfusion chamber. A preheating coil of nichrome wire surrounded the tubing just upstream of the chamber to warm the bathing buffer to $34^{\circ} \mathrm{C}$ before reaching the chamber and thereby to eliminate a large temperature gradient that otherwise existed along the axis of the perfusion chamber. Transmural potential difference (PD) was measured by coupling the bath (reference potential) and perfusion pipette lumen to separate a $3 \mathrm{M} \mathrm{KCl}$ reservoirs with saline $(150 \mathrm{mM} \mathrm{NaCl}) 3 \%$ agarose bridges. Calomel electrodes were immersed in the $\mathrm{KCl}$ reservoirs and the voltage difference between the electrodes was input to a unity gain amplifier with $>10^{15} \Omega$ input impedance (VF-2, World Precision Instruments Inc., Sarasota, FL).

Vasa recta and thin limbs segments were obtained from the kidneys of weanling Sprague-Dawley rats (Harlan Sprague Dawley, Indianapolis, IN). These animals were given intraperitoneal (i.p.) bolus injections of furosemide (5 mg i.p.) 20-30 min before sacrifice (14) and anesthetized by i.p. injection of thiopental $(50 \mathrm{mg} / \mathrm{kg}$ body wt) before removal of the kidneys. Microvessels and nephron segments were dissected under a stereomicroscope (Nikon model SMZ-2B) and trans- ferred to the stage of the inverted microscope. OMVR, the descending limb of long-looped nephrons (LDLu), and thick ascending limbs (TALH) were dissected from tissue maintained at $0-4^{\circ} \mathrm{C}$. Attempts to dissect thin ascending limbs (tALH) at this low temperature were consistently accompanied by sloughing of the epithelium from the basement membrane. This occurred in either KRB or Hepes buffers with or without furosemide pretreatment (see below). Thin ascending limbs were therefore dissected at room temperature with apparently excellent preservation of epithelial integrity. The OMVR perfused in these studies were always dissected from within vascular bundles. Bundles were located by grasping tissue at the corticomedullary junction and peeling successive strips away until a bundle was entered. Attempts to dissect vasa recta in the outer medullary interbundle region or the inner medulla were unsuccessful. Initially, OMVR were perfused only if they could be identified by the presence of red blood cells (RBCs) in their lumens. It quickly became apparent that the appearance of these vessels under the dissecting microscope and during perfusion was unique. They are readily identified by their small size and irregular cellular structure of their walls (Fig. 1). Only a few OMVR in tissue slices contained RBCs and this criterion was abandoned. The LDLu was identified by its large tapering diameter, large regular cellular structure, and characteristic tortuosity (Fig. 1). The TALH was identified by its generally straight appearance and characteristic thin epithelium. The identity of tALH was always verified by its contiguity with the TALH. The tALH can also be distinguished from inner medullary descending thin limbs by the protrusion of some of their epithelial cells beyond the tubule wall making the wall exterior appear irregular (Fig. 1). tALHs were perfused by drawing a portion of the TALH into the holding pipette and advancing the inner perfusion pipette beyond the TALH lumen.

The thin descending limb of short-looped nephrons (SDL) in the rat arises from the pars recta and migrates toward the periphery of
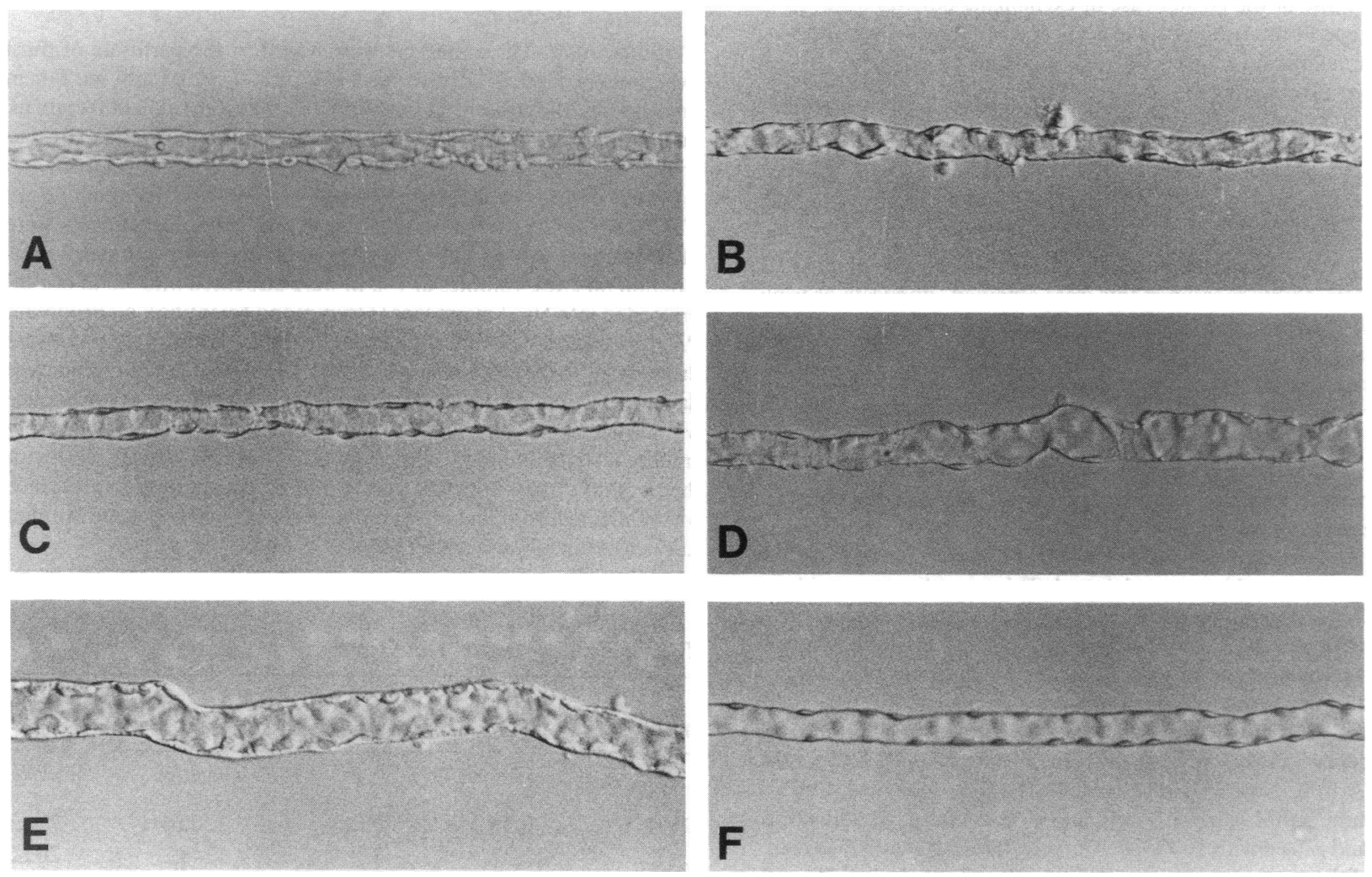

Figure 1. Light micrographic appearance of OMVR and thin limbs. $(A-D)$ Four photos of OMVR demonstrate the variation in their appearance size and cellularity. $(E)$ Thin descending limb of long-looped nephron (LDLu) dissected from the outer medulla. $(F)$ Thin ascending limb (tALH) dissected from just below the inner-outer medullary junction. 
vascular bundles $(2,6)$. These segments are smaller than the $\mathrm{LDL}_{u}$ and have a thinner epithelium. The SDL can be distinguished from OMVR by its larger outer diameter, regularity of its cellular structure and clarity of its cytoplasm. Also, unlike the vasa recta, nuclei of the SDL do not indent the periphery so that the SDL has a smoother appearance. In our experience the SDL does not separate with the vascular bundles during dissection but remains with other nephron segments in the interbundle region of the inner stripe. Several attempts were made to dissect and perfuse sufficiently long SDL segments for permeability measurements. Those efforts were unsuccessful.

The construction of pipettes to perfuse OMVR proved to be difficult. Holding pipettes have outside diameters of 13-15 $\mu \mathrm{m}$ and inner constrictions of 6-9 $\mu \mathrm{m}$. The latter feature required perfusion pipettes to be of small diameter (4-6 $\mu \mathrm{m})$. Some OMVR were deliberately not selected at the time of dissection due to their obvious small diameter because further reduction of perfusion pipette diameter would have necessitated inordinately high hydraulic pressures to achieve the perfusion rates required for these studies $(15-30 \mathrm{nl} / \mathrm{min})$. This avoidance may introduce selection bias.

The most critical aspect of successful OMVR perfusion was fitting the collection pipette to achieve a good seal while avoiding excessive constriction of the vessel. This was eventually accomplished by constructing collection pipettes in three size ranges (4-6, 6-9, and 9-12 $\mu \mathrm{m})$ and trying pipettes until a good fit was achieved. Sylgard 184 silicon polymer (Dow Corning Corp., Midland, MI) was polymerized to a small area of the collection pipette entrance region. The use of additional unpolymerized liquid Sylgard on the pipette interior proved to be too constricting to achieve rapid perfusions so that DC 200 silicone oil ( 50 centistokes) (Dow Corning) was used in its place, a strategy used by Chou and Knepper (14) to perfuse inner medullary thin limbs. Some experiments were performed using an outer guard pipette to achieve a collection seal (13). Sylgard 184 was polymerized onto the guard pipette and the pipette filled with DC 200 silicone oil. Either the inner or outer Sylgard method worked adequately. The former is preferred because of the greater ease of exchanging pipettes for good fit. Once a good fit was achieved, the distal end of the vessel was drawn in slightly to eliminate transport across endothelium possibly damaged during pipette exchanges.

Collections of vessel or tubule effluent were obtained with constriction pipettes of about $100 \mathrm{nl}$. Timed collections were performed to determine collection rate $\left(Q_{c}\right)$. Perfusion rate $\left(Q_{o}\right)$ was determined from the product of $\mathrm{Q}_{\mathrm{c}}$ and the collectate-to-perfusate volume marker, fluorescein isothiocyanate-labeled dextran (FITC-Dx) concentration ratio, $R_{D x}$. OMVR and tubules were perfused for $20-30 \mathrm{~min}$ at $37^{\circ} \mathrm{C}$ before permeability measurements were obtained (duplicate or triplicate determinations).

Initially, the fluorescence in the bath was routinely monitored. Bath fluorescence was always zero and the practice of monitoring bath fluorescence was eventually abandoned. Given the dilution factor involved (perfusion rate $15-30 \mathrm{nl} / \mathrm{min}$, bath flow rate $3 \times 10^{5} \mathrm{nl} / \mathrm{min}$ ) it might be impossible to detect a sizable perfusate leak by this method. During pilot experiments, examinations of perfused OMVR were performed under fluorescent microscopy. The vessel was observed for accumulation of fluorescence in the outside vicinity of its wall when the bath flow rate was set to zero. None was detected. This provides some evidence that the $2 \times 10^{6} \mathrm{~mol}$ wt of the FITC-Dx volume marker is adequate to prevent permeation of the OMVR wall. To avoid photobleaching of FITC, visual examinations under fluorescent microscopy were not performed during permeability measurements.

OMVR were most often dissected and perfused in the following buffer: Hepes $5 \mathrm{mM}, \mathrm{NaCl} 140 \mathrm{mM}, \mathrm{Na}$ acetate $10 \mathrm{mM}, \mathrm{KCl} 5 \mathrm{mM}$, $\mathrm{MgCl}_{2} 1.2 \mathrm{mM}, \mathrm{Na}_{2} \mathrm{HPO}_{4} 1.71 \mathrm{mM}, \mathrm{NaH}_{2} \mathrm{HPO}_{4} 0.29 \mathrm{mM}, \mathrm{CaCl}_{2} 1$ $\mathrm{mM}$, alanine $5 \mathrm{mM}$, glucose $5 \mathrm{mM}$, and albumin $0.5 \mathrm{~g} / \mathrm{dl}$, adjusted to $\mathrm{pH} 7.4$, and gassed with $100 \% \mathrm{O}_{2}$. The bath flow rate was $300 \mu \mathrm{l} / \mathrm{min}$. In view of the concerns expressed by Flessner and colleagues (15) with regard to the alteration of transport properties of nephron segments perfused with organic buffers, a KRB buffer was used for perfusion of some OMVR and all loop of Henle segments: $\mathrm{NaCl} 115 \mathrm{mM}$; Na ace- tate $10 \mathrm{mM}, \mathrm{NaHCO}_{3} 25 \mathrm{mM}, \mathrm{KCl} 5 \mathrm{mM}, \mathrm{MgCl}_{2} 1.2 \mathrm{mM}, \mathrm{Na}_{2} \mathrm{HPO}_{4}$ $1.71 \mathrm{mM}, \mathrm{NaH}_{2} \mathrm{HPO}_{4} 0.29 \mathrm{mM}, \mathrm{CaCl}_{2} 1 \mathrm{mM}$, alanine $5 \mathrm{mM}$, glucose 5 $\mathrm{mM}$, gassed with $95 \% \mathrm{O}_{2} / 5 \% \mathrm{CO}_{2}$, and adjusted to $\mathrm{pH}$ 7.4. $\mathrm{KRB}$ bath flow rate was $750 \mu \mathrm{l} / \mathrm{min}$. Tubing that carried bath to the perfusion chamber was jacketed with larger concentric tubing to enable superfusion with the gas appropriate to the buffer.

In vivo. Female Munich-Wistar rats (Harlan Sprague Dawley) weighing 70-120 g were allowed free access to food and water until the time of the experiment. Anesthesia was obtained by an i.p. injection of Inactin (Andrew Lockwood, E. Lansing, MI), $100 \mathrm{mg} / \mathrm{kg}$ body wt. The rats were placed on a heated table and body temperature maintained between $36^{\circ} \mathrm{C}$ and $38^{\circ} \mathrm{C}$ as measured by rectal probe. For infusions and bolus injections, the jugular vein was cannulated with PE-50 tubing that had been tapered by pulling over a flame. A tracheostomy was performed, the left femoral artery cannulated for blood pressure monitoring, and a bladder catheter inserted to measure urine flow from the right kidney. The papilla of the left kidney was prepared for micropuncture as previously described $(7,10,11,16,17)$. After surgery, a 30-min equilibration period was permitted to elapse before microperfusion was performed.

Animals were subjected to furosemide and saline diuresis as previously described (17). Blood pressure and urinary flow rate were monitored with each experiment (Table I).

Individual vasa recta were isolated and subjected to free-flow microperfusion by isolating them on the papillary surface as previously described (16). The vessels were blocked with paraffin wax and perfused from papillary tip toward the base. AVR perfusions were performed at $20 \mathrm{nl} / \mathrm{min}$ and DVR at $10 \mathrm{nl} / \mathrm{min}(10,11)$ by using a calibrated nanoliter perfusion pump. The distance from the perfusion to collection sites was measured with an ocular micrometer.

The buffer used for in vivo microperfusion of papillary vasa recta during furosemide and saline diuresis is identical to that previously described $(10,11)$.

\section{Analytical methods}

Perfusion fluid. Three markers were added to the perfusate of most experiments, ${ }^{22} \mathrm{Na},\left[{ }^{14} \mathrm{C}\right]$ urea, and FITC-Dx $2 \times 10^{6} \mathrm{~mol} \mathrm{wt}$. For in vivo studies, the concentrations were $\sim 1,000 \mathrm{cpm} / \mathrm{nl}, 3,000 \mathrm{cpm} / \mathrm{nl}$, and $5 \mathrm{mg} / \mathrm{ml}$, respectively. For in vitro perfusion, the marker concentrations were $15 \mathrm{cpm} / \mathrm{nl}, 50 \mathrm{cpm} / \mathrm{nl}$, and $200 \mu \mathrm{g} / \mathrm{ml}$, respectively.

Dual-isotope counting of ${ }^{22} \mathrm{Na}$ and $\left[{ }^{14} \mathrm{C}\right]$ urea and microanalysis of FITC-Dx. For in vivo work, perfusate and collectate samples were placed under water-equilibrated mineral oil. By using volumetric constriction pipettes, volumes of 1-2 $\mathrm{nl}$ were dispensed into $7.5 \mu \mathrm{l}$ of PBS preloaded into 50- $\mu \mathrm{l}$ microcaps (Drummond Scientific Co., Broomall, PA) that had been cut in half. For in vitro work, samples of $100 \mathrm{nl}$ were dispensed into the same volume of PBS. The ends of the microcap were flame-sealed and centrifuged back and forth for mixing. Fluorescence was measured using a photon counting microscope detection assembly (model D104B, Photon Technology Int., South Brunswick, NJ) with the photomultiplier tube charged to $950 \mathrm{~V}$. Background fluorescence was subtracted from that measured in perfusate and collectate samples to calculate the fluorescence (16).

Table I. Whole-Animal Data from In Vivo Microperfusions

\begin{tabular}{lcccc}
\hline Group & $\mathrm{N}_{2} / \mathrm{N}_{\mathrm{v}}$ & Weight & MAP & $\begin{array}{c}\text { Urine } \\
\text { flow }\end{array}$ \\
\hline & & $g$ & $m m H g$ & $\mu l / m i n$ \\
DVR & $8 / 15$ & $89 \pm 3$ & $120 \pm 4$ & $26 \pm 3$ \\
AVR & $11 / 18$ & $87 \pm 3$ & $124 \pm 2$ & $26 \pm 2$ \\
\hline
\end{tabular}

Abbreviations: $N_{a}$ and $N_{v}$, number of animals and number of vessels, respectively; MAP, mean arterial pressure. 
After measurement of fluorescence, the cuvettes were subjected to dual-isotope counting of ${ }^{22} \mathrm{Na}$ and $\left[{ }^{14} \mathrm{C}\right]$ urea. The end of the microcap containing the samples was cut off and placed into scintillation vials containing $7.5 \mathrm{ml}$ of Aquasol (New England Nuclear, Boston, MA). By using needlenose pliers, the cuvettes were crushed until all sample was released. The pliers were touched to the side of the vial until all scintillation fluid drained off. Vials were capped, shaken, and counted in a model LS 3801 liquid scintillation counter (Beckman Instruments, Inc. Palo Alto, CA). Taking advantage of the $\beta$ and $\gamma$ emissions of ${ }^{22} \mathrm{Na}$, in many experiments (see below), cuvettes were also counted (before crushing) in a Beckman Instruments model $5500 \gamma$ counter. This enabled ${ }^{22} \mathrm{Na}$ to be measured alone, independent of ${ }^{14} \mathrm{C}$. In a series of experiments in which volumes of ${ }^{22} \mathrm{Na}$ were added to a constant amount of $\left[{ }^{14} \mathrm{C}\right]$ urea, it was determined that a lower liquid scintillation counting window (Beckman Instruments, $0-655$ ) contained all ${ }^{14} \mathrm{C} \beta$ emissions and $48.7 \%$ of the ${ }^{22} \mathrm{Na} \beta$ emissions. The upper window (6551000) contained only ${ }^{22} \mathrm{Na}$. Thus, to determine the activity of ${ }^{14} \mathrm{C}$, $195 \%$ of counts in the upper window were subtracted from counts in the lower window. The activity of ${ }^{22} \mathrm{Na}$ was taken as counts in the upper window alone. Fig. 2 shows collectate-to-perfusate ${ }^{22} \mathrm{Na}$ ratio $\left(R_{\mathrm{Na}}\right)$ in 158 samples measured by $\gamma$ counting (before crushing the cuvette) and by $\beta$ counting (after crushing the cuvette). These data are from thin limb and vasa recta perfusions performed in vivo and in vitro. The correlation was excellent. The ability to measure ${ }^{14} \mathrm{C}$ in the presence of ${ }^{22} \mathrm{Na}$ was verified by adding $1-5$ vol of ${ }^{14} \mathrm{C}$ to a constant amount of ${ }^{22} \mathrm{Na}$. As shown in Fig. 2 (left panel), the ability to recover $\left[{ }^{14} \mathrm{C}\right]$ urea in 10 samples by dual-isotope $\beta$ counting was indistinguishable from $100 \%$.

Fluorescent microassay of urea. A fluorescent microassay based on the urease method was employed for measurement of nonisotpic urea. The use of this reaction for microanalysis of urea and ammonia has been described ( 18). Reagents were purchased as a kit from Boehringer Mannheim Biochemicals, Indianapolis, IN (catalog no. 542946) and prepared according to the instructions. The method relies upon measurement of fluorescence reduction due to the consumption of NADH in an amount stochiometrically equivalent to the urea present in the sample. By using volumetric constriction pipettes of about $30 \mathrm{nl}$, samples were injected into $50-\mu l$ microcaps (Drummond Scientific) that had been cut in half and preloaded with $7.5 \mu \mathrm{l}$ of reagent. These microcaps were flame-sealed and centrifuged back and forth for mixing. A specialized acrylic holder was constructed to allow the cuvettes to be placed on the stage of a Nikon Diaphot. The Diaphot is equipped with

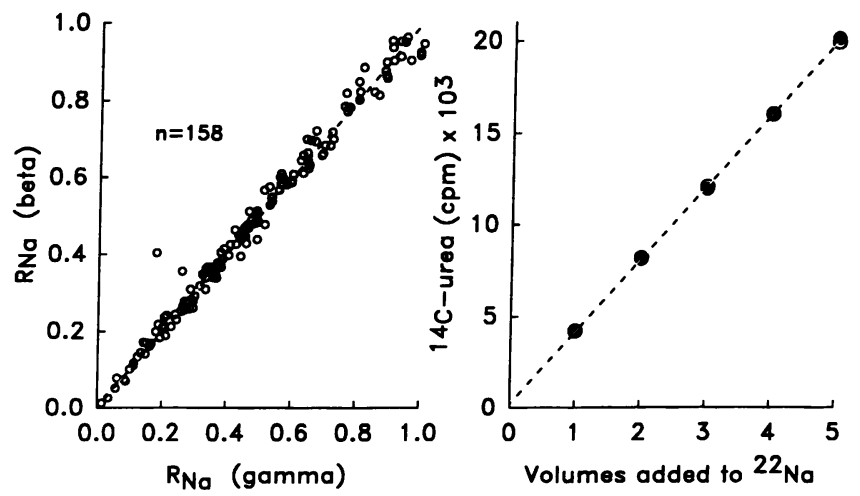

Figure 2. Dual-isotope counting of ${ }^{22} \mathrm{Na}$ and $\left[{ }^{14} \mathrm{C}\right]$ urea. Left panel: To verify the ability to measure ${ }^{22} \mathrm{Na}$ in the presence of ${ }^{14} \mathrm{C}$, the collectate-to-perfusate ratio of ${ }^{22} \mathrm{Na}\left(R_{\mathrm{Na}}\right.$, ordinate and abscissa) of 158 samples obtained from perfused OMVR, inner medullary AVR and DVR, or thin limbs was determined by $\gamma$ counting and then $\beta$ counting. The dashed line is the line of identity. Right panel: To verify the ability to recover ${ }^{14} \mathrm{C}$ in the presence of ${ }^{22} \mathrm{Na}, 1-5 \mathrm{vol}$ of $\left[{ }^{14} \mathrm{C}\right]$ urea were added to fluid already containing ${ }^{22} \mathrm{Na}$ (duplicate determinations). variable fluorescent excitation from a Xenon lamp and scanning monochrometer (Photon Technology Int., model FM100). The cuvettes were excited at $350 \mathrm{~nm}$ and the emission monitored with a filter set containing a $400-\mathrm{nm}$ dichroic mirror and $510 \mathrm{~nm}$ emission filter. Fluorescence from the samples was measured with a photon counting detection assembly. Fig. 3 shows the reduction in fluorescence achieved with urea standards of increasing concentration. The assay was linear from 0 to $7.5 \mathrm{mM}$ urea. Based on Fig. $3,5 \mathrm{mM}$ was chosen as the perfusate urea concentration for permeability measurements with "chemical" urea.

Osmolalities were measured by the Ramsey-Brown microfreezing point method (19).

Permeability measurements. Permeability to the $i$ th solute was calculated from perfusion rate $\left(Q_{\mathrm{o}}\right)$, diameter $(D)$, length $(L)$, and collectate-to-perfusate ratio of the marker $\left(R_{i}\right)$ from,

$P_{i}=\frac{Q_{\mathrm{o}}}{\prod D L}\left\{\ln \left(\frac{1}{R_{i}}\right)\right\}$

\section{Electron microscopy}

Descending and ascending vasa recta are present in outer medullary vascular bundles. In the rabbit and human, endothelia have been shown to be continuous and fenestrated, respectively $(5,20)$. A major difficulty with interpretation of in vitro microperfusion data from OMVR is the identification of the type of vas rectum being studied (DVR or AVR). To address this issue, the first 50 OMVR whose permeabilities were measured were also photographed with differential interference contrast optics. At random, seven vessels were also recovered after perfusion and subjected to transmission electron microscopy (TEM). To verify that outer medullary AVR in the rat are also fenestrated, a wedge of tissue containing a vascular bundle was recovered, fixed and examined by TEM.

The method used to recover vessels for TEM was similar to that described by Imai et al. (21). While being perfused, the OMVR were fixed by exchanging the bath with $2 \%$ glutaraldahyde in $100 \mathrm{mM}$ cacodylate buffer, pH 7.4 (Sigma Chemical Co., St. Louis, MO). The vessels were expelled from the pipettes or pipette tips were broken off on the bottom of the chamber. Fixed OMVR were transferred to the same cold fixative in microtiter plates (Sigma). Glutaraldahyde was removed by three exchanges of $100 \mathrm{mM}$ cacodylate buffer. The OMVR were then placed in a well containing $1 \% \mathrm{OsO}_{4}$ in $100 \mathrm{mM}$ cacodylate. The osmium was removed by three exchanges of buffer. $1 \%$ agarose (Sigma) was placed on a microscope coverslip and the OMVR transferred onto the agarose. A few additional microliters of liquid agarose were dripped onto the OMVR to embed it. The embedded OMVR was then subjected to graded ethanol dehydration followed by final dehydration in propylene oxide. The specimen was embedded, sectioned, and subjected to transmission electron microscopy to search for fenestrations.

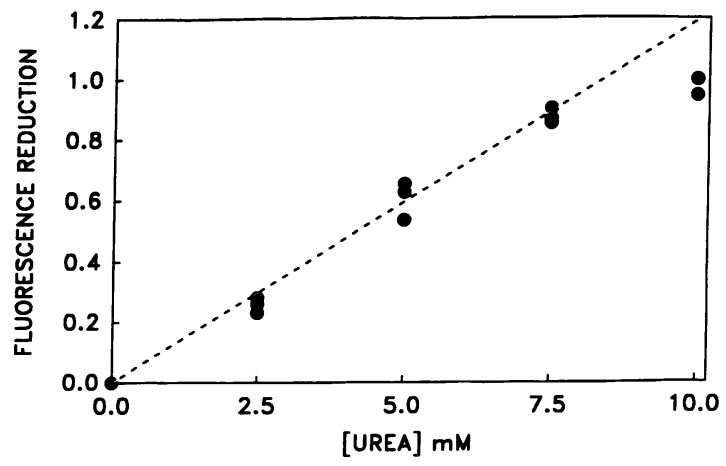

Figure 3. Microanalysis of urea by the urease reaction. Fluorescence reduction produced by consumption of NADH is shown as a function of urea concentration in five standards. The assay is linear from 0 to $7.5 \mathrm{mM}$ urea. 
Table II. Data from Perfusion of Renal Medullary Microvascular and Nephron Segments

\begin{tabular}{|c|c|c|c|c|c|}
\hline & IM-AVR & IM-DVR & OMVR & LDLu & tALH \\
\hline Number & 18 & 15 & 60 & 6 & 6 \\
\hline Length $(\mu m)$ & $475 \pm 36$ & $535 \pm 52$ & $348 \pm 11$ & $687 \pm 87$ & $665 \pm 26$ \\
\hline Diameter $(\mu m)$ & - & - & $12.9 \pm 0.3$ & $24.9 \pm 0.7$ & $19.2 \pm 0.4$ \\
\hline $\mathrm{Q}_{\mathrm{o}}($ nl/min $)$ & 20 & 10 & $20.1 \pm 0.8$ & $17.5 \pm 1.6$ & $10.9 \pm 0.4$ \\
\hline $\mathbf{R}_{\mathbf{D x}}$ & $1.03 \pm 0.03$ & $1.03 \pm 0.03$ & $1.00 \pm 0.01$ & $1.00 \pm 0.02$ & $1.01 \pm 0.01$ \\
\hline $\mathbf{R}_{\mathrm{Na}}$ & $0.41 \pm 0.03$ & $0.32 \pm 0.04$ & $0.71 \pm 0.03$ & $0.35 \pm 0.06$ & $0.38 \pm 0.01$ \\
\hline $\mathbf{R}_{\mathbf{u}}$ & $0.39 \pm 0.03$ & $0.33 \pm 0.05$ & $0.19 \pm 0.01$ & $1.00 \pm 0.01$ & $0.59 \pm 0.05$ \\
\hline $\mathbf{P}_{\mathrm{Na}}\left(\times 10^{-5}, \mathrm{~cm} / \mathrm{s}\right)$ & $115 \pm 10$ & $75 \pm 10$ & $76 \pm 9$ & $63 \pm 4$ & $45 \pm 2$ \\
\hline $\mathrm{P}_{\mathrm{u}}\left(\times 10^{-5}, \mathrm{~cm} / \mathrm{s}\right)$ & $121 \pm 10$ & $76 \pm 11$ & $360 \pm 14$ & $0.5 \pm 0.2$ & $25 \pm 3$ \\
\hline
\end{tabular}

Abbreviations: IM-AVR, IM-DVR, inner medullary ascending and descending vasa recta, respectively; OMVR, outer medullary vasa recta; LDLu, upper (outer medullary) portion of thin descending limb of long loop nephron; $t A L H$, thin ascending limb; $Q_{0}$, perfusion rate; $R_{D x}, R_{N a}$, and $R_{u}$, collectate-to-perfusate ratio of dextran, ${ }^{22} \mathrm{Na}$, and $\left[{ }^{14} \mathrm{C}\right]$ urea, respectively; $\mathrm{P}_{\mathrm{Na}}$ and $\mathrm{P}_{\mathrm{u}}$, permeability to ${ }^{22} \mathrm{Na}$ and $\left[{ }^{14} \mathrm{C}\right]$ urea. Data are mean \pm SE.

\section{Statistical analysis}

Experimental results are reported as mean \pm SE. Statistical comparisons employ paired $t$ test, unpaired $t$ test, or repeated measures ANOVA as appropriate. In the latter case, Bonferonni $t$ test, Student-NewmanKeuls test, and Dunnett's test were all examined to establish significance. No discrepancies between these tests were found.

\section{Results}

Inner Medullary Vasa Recta Permeability to ${ }^{22} \mathrm{Na}$ and $\left[{ }^{14} \mathrm{C}\right]$ urea. Mean $\pm \mathrm{SE}$ of microperfusion data from in vivo experiments are presented in Table II and the sodium and urea permeabilities are illustrated in Fig. 4. The ${ }^{22} \mathrm{Na}$ permeabilities $\left(P_{\mathrm{Na}}\right)$ of papillary DVR and AVR are similar to previously determined values $(10,11)$. For the first time, urea permeability $\left(P_{u}\right)$, is also provided. In the papillary AVR, $P_{u}$, was always slightly greater than $P_{\mathrm{Na}}$ in identical vessels $(P<0.001) . \mathrm{P}_{\mathrm{u}}$ and $P_{\mathrm{Na}}$ were indistinguishable in DVR (Table II and Fig. 4).

OMVR to ${ }^{22} \mathrm{Na}$ and ${ }^{14} \mathrm{C}$-urea. From the beginning of this study, it was apparent that the properties of OMVR varied at

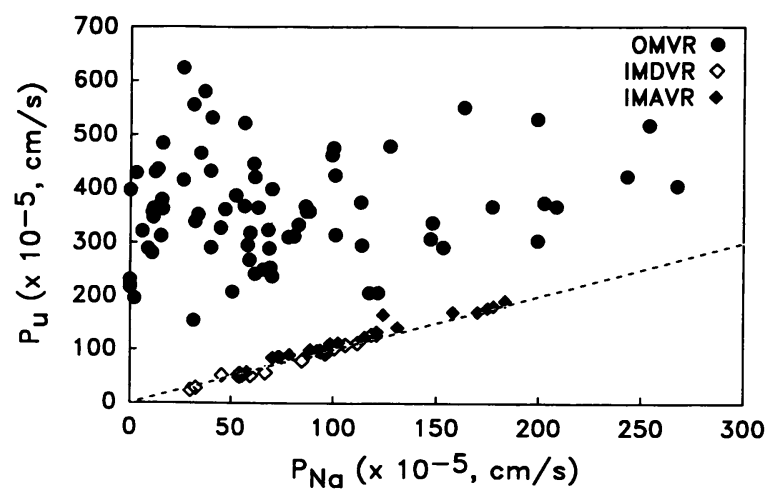

Figure 4. Simultaneous determination of $\mathrm{P}_{\mathrm{Na}}$ and $\mathrm{P}_{\mathrm{u}}$ in outer and inner medullary vasa recta. Urea permeability $\left(P_{u}\right.$, ordinate $)$ is shown as a function of sodium permeability $\left(P_{N a}\right.$, abscissa $)$ in OMVR, inner medullary DVR (IMDVR), and inner medullary AVR (IMAVR). There was no correlation between permeabilities in OMVR whereas $P_{\mathrm{Na}}$ and $\mathbf{P}_{\mathbf{u}}$ were highly correlated in the inner medulla. The dashed line is the line of identity. least as much as those of vasa recta at the papillary tip $(10,11)$. To determine if a bimodal distribution of properties existed, a large number of OMVR were initially studied $(n=60)$. Mean values are shown in Table II. A striking feature of OMVR is their extremely high permeability to $\left[{ }^{14} \mathrm{C}\right]$ urea. In contrast to inner medullary vasa recta, $P_{u}$ often exceeded $P_{N a}$ in the same vessel by orders of magnitude.

To assure that a PD, neglected by Eq. 1, did not affect measurement of sodium permeability, PD was measured along with tracer effluxes in eight OMVR. PD in OMVR was statistically indistinguishable from zero. As a test of our ability to measure PD, the TALH was perfused in the presence of 20 $\mu \mathrm{U} / \mathrm{ml}$ antidiuretic hormone (ADH). As described by others $(22,23)$ PD was consistently lumen positive (Table III).

To assure that the absence of bicarbonate did not distort the properties of OMVR, permeability measurements were also performed in eight vessels perfused with KRB buffer. The extremely high urea permeability was reproduced in those experiments (Table IV).

To assure that the high urea permeabilities were not due to degradation of the $\left[{ }^{14} \mathrm{C}\right]$ urea tracer, 10 additional experiments were performed in which OMVR urea permeability was measured from efflux of $5 \mathrm{mM}$ chemical urea. $P_{u}$ was determined by fluorescent microanalysis of urea in the perfusate and collectate with the urease reaction (see Methods and Fig. 3). A similarly high permeability to urea was found (Table V).

Table III. Transmembrane Potential Difference during Perfusion of $O M V R$

\begin{tabular}{lcc}
\hline & OMVR & TALH \\
\hline Number & 8 & 8 \\
$\mathrm{Q}_{\mathrm{o}}(\mathrm{nl} / \mathrm{min})$ & $17.6 \pm 2.8$ & $10.3 \pm 0.5$ \\
$\mathrm{R}_{\mathrm{Dx}}$ & $0.99 \pm 0.03$ & - \\
$\mathrm{R}_{\mathrm{Na}}$ & $0.82 \pm 0.07$ & - \\
$\mathrm{R}_{\mathrm{u}}$ & $0.13 \pm 0.02$ & - \\
$\mathrm{P}_{\mathrm{Na}}\left(\times 10^{-5}, \mathrm{~cm} / \mathrm{s}\right)$ & $45 \pm 14$ & - \\
$\mathrm{P}_{\mathrm{u}}\left(\times 10^{-5}, \mathrm{~cm} / \mathrm{s}\right)$ & $399 \pm 23$ & - \\
$\mathrm{PD}(\mathrm{mV})$ & $0.2 \pm 0.2$ & $8.1 \pm 0.8$ \\
\end{tabular}

Abbreviations as in Table II. Data are mean \pm SE. 
Table IV. Permeability of OMVR during Perfusion with KRB Buffer

\begin{tabular}{lc}
\hline Number & 8 \\
$\mathrm{Q}_{\mathrm{o}}(\mathrm{nl} / \mathrm{min})$ & $21.5 \pm 2.9$ \\
$\mathbf{R}_{\mathrm{Dx}}$ & $1.08 \pm 0.04$ \\
$\mathrm{R}_{\mathrm{Na}}$ & $0.74 \pm 0.05$ \\
$\mathrm{R}_{\mathrm{u}}$ & $0.21 \pm 0.04$ \\
$\mathrm{P}_{\mathrm{Na}}\left(\times 10^{-5}, \mathrm{~cm} / \mathrm{s}\right)$ & $71 \pm 14$ \\
$\mathrm{P}_{\mathrm{u}}\left(\times 10^{-5}, \mathrm{~cm} / \mathrm{s}\right)$ & $400 \pm 42$ \\
\hline
\end{tabular}

Abbreviations as in Table II. Data are mean \pm SE.

Frequency distribution of OMVR permeability to ${ }^{22} \mathrm{Na}$ and ${ }^{14} \mathrm{C}$ ] urea. $\mathrm{P}_{\mathrm{Na}}$ and $\mathrm{P}_{\mathrm{u}}$ were simultaneously measured in a total of 76 OMVR (Tables II-IV). These data are included with inner medullary measurements in Fig. 4. A striking feature is the frequent low permeability of OMVR to ${ }^{22} \mathrm{Na}$. Some OMVR had $\mathrm{P}_{\mathrm{Na}}$ indistinguishable from zero; in sharp contrast all had $P_{u}$ higher than that of the vasopressin-stimulated inner medullary collecting duct $(24,25)$. In Fig. 5 , the frequency distribution of permeability properties in the 76 OMVR are shown. The distribution is unimodal.

Loop of Henle transport. As a test of the microperfusion and dual-isotope counting technique, thin limb segments known to be selectively permeable to sodium over urea were examined. Six LDLu had a $P_{N a}$ of $63 \pm 4$ with simultaneous $P_{u}$ indistinguishable from zero. This provides additional evidence for the integrity of the ${ }^{14} \mathrm{C}$ radiolabel. Six tALH also showed selectivity favoring passive transport of sodium (Table II and Fig. 6). Other investigators have shown $P_{\mathrm{Na}}$ to exceed $P_{u}$ in the LDLu of hamsters $(21,26)$ and chinchilla $(27)$, as well as the tALH of the rat (28). The low permeability of the LDLu to urea has been reported in the hamster $\left(P_{u}=1.5 \times 10^{-5} \mathrm{~cm} / \mathrm{s}\right)$ (21) and chinchilla $\left(P_{u}=3.3 \times 10^{-5} \mathrm{~cm} / \mathrm{s}\right)(27)$. This lends confidence to the reliability of the present methods. Transmembrane potential difference was not monitored in these experiments, however, it has been reported to be zero in thin limbs of the rat $(28,29)$ and other species $(21,28-30)$.

Evidence for facilitated transport of urea. The marked difference between the urea permeabilities of inner and outer medullary vasa recta suggests the possibility that OMVR and inner medullary vasa recta transport urea by different pathways. To examine this, five vessels were perfused with $0 \mathrm{mM}$ urea (control and recovery periods) or $200 \mathrm{mM}$ urea (experimental period) in the bath and perfusate. As shown in the left panel of Fig. 7, apparent urea permeability to $\left[{ }^{14} \mathrm{C}\right]$ urea fell during the experimental period. This suggests competition of unlabeled urea with the $\left[{ }^{14} \mathrm{C}\right]$ urea tracer for a carrier. To assure that these

Table V. Urea Permeability of OMVR Determined by Fluorescent Assay of Urea

\begin{tabular}{lc}
\hline Number & 10 \\
$\mathrm{Q}_{\mathrm{o}}(\mathrm{nl} / \mathrm{min})$ & $38.8 \pm 4.0$ \\
$\mathrm{R}_{\mathrm{Dx}}$ & $1.04 \pm 0.04$ \\
$\mathrm{R}_{\mathrm{u}}$ & $0.40 \pm 0.03$ \\
$\mathrm{P}_{\mathrm{u}}\left(\times 10^{-5}, \mathrm{~cm} / \mathrm{s}\right)$ & $385 \pm 16$ \\
\hline
\end{tabular}

Abbreviations as in Table II. Data are mean \pm SE.
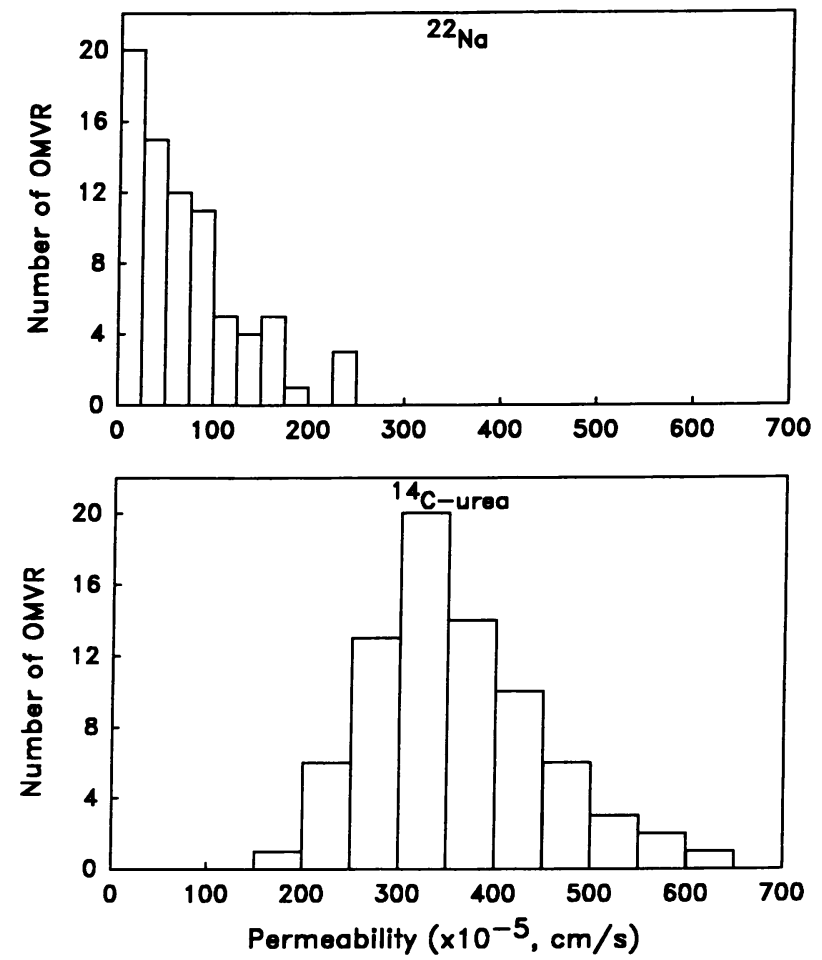

Figure 5. Frequency histogram of OMVR transport properties. Top panel: The number of OMVR (ordinate) lying within the $P_{\mathrm{Na}}$ values on the abscissa is given. Bottom panel: The number of OMVR (ordinate) lying within the $P_{u}$ values on the abscissa. Unimodal distributions characterize the permeabilities of both solutes.

results were not due to a nonspecific effect of increasing osmolality during the experimental period, additional experiments were performed in which $0.25 \mathrm{mM}$ phloretin, a known inhibitor of facilitated urea transport in RBC (31) and the inner medullary collecting duct $(24,32)$ was included in the bath and lumen during the experimental period. Urea efflux was reversibly inhibited by phloretin (Fig. 7, right panel). In these experiments, the contribution of $\left[{ }^{14} \mathrm{C}\right]$ urea isotope to total urea concentration was $<1 \mathrm{mM}$ as determined with the urease reaction, (see Methods and Fig. 3).

OMVR identification. 50 perfused OMVR were photographed. Wall thickness, number of nuclei per unit length or diameter failed to predict which were likely to have a low $\mathbf{P}_{\mathrm{Na}}$.

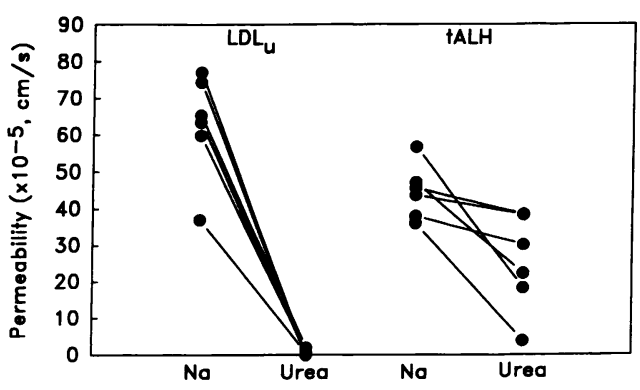

Figure 6. Simultaneous determination of $\mathrm{P}_{\mathrm{Na}}$ and $\mathrm{P}_{\mathrm{u}}$ in the LDLu and tALH. $P_{\mathrm{Na}}$ and $\mathrm{P}_{\mathrm{u}}$ were determined in six thin descending limbs of long-looped nephrons dissected from the outer medulla (LDLu) and six thin ascending limbs (tALH). Lines connect values of the same limbs. 

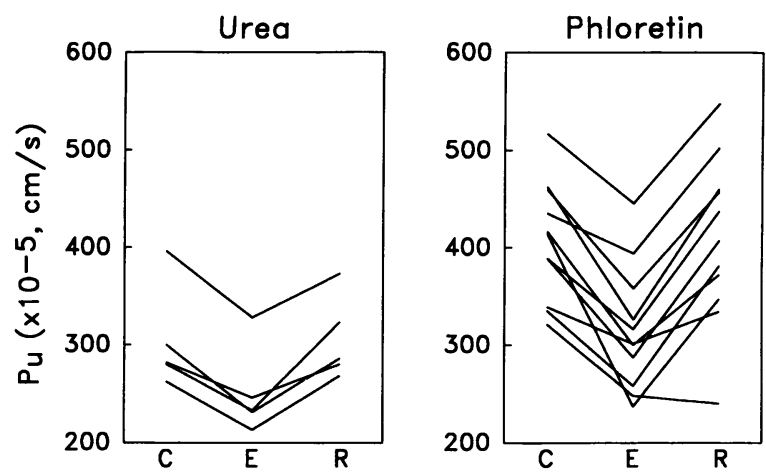

Figure 7. Inhibition of OMVR $\left[{ }^{14} \mathrm{C}\right]$ urea transport by urea and phloretin. Left panel: Apparent urea permeability (ordinate) was measured from efflux of $\left[{ }^{14} \mathrm{C}\right]$ urea. During the experimental period, $200 \mathrm{mM}$ urea was added to the bath and perfusate. Right panel: Apparent urea permeability measured from $\left[{ }^{14} \mathrm{C}\right]$ urea efflux measured in the absence and presence of $0.25 \mathrm{mM}$ phloretin. Abbreviations: $C$, control; $E$, experimental; $R$, recovery.

Prospective attempts to predict a low $\mathrm{P}_{\mathrm{Na}}$ based on the appearance of the vessel failed uniformly.

It was impractical to subject all OMVR studied to TEM to search for the continuous or fenestrated endothelial structure that would identify them as DVR or AVR, respectively $(5,20)$. A sampling of seven vessels examined by TEM disclosed that all had a continuous structure, identifying them as outer medullary DVR traversing vascular bundles. A representative electron micrograph is shown in Fig. 8. The $\mathrm{P}_{\mathrm{Na}}$ of the OMVR subjected to TEM were $\left(\times 10^{-5} \mathrm{~cm} / \mathrm{s}\right) 27,88,4,37,88,71$, and 30 .

To verify that AVR from vascular bundles in the outer medulla of the rat are fenestrated, a wedge of tissue containing vascular bundles was dissected, fixed, and examined by TEM. Fenestrated vessels do exist in vascular bundles of the rat (Fig. 9).

Finally, evidence that the vessels perfused in this study are branches of the juxtamedullary efferent arteriole has been obtained by observing their contraction (Fig. 10) upon exposure to $10 \mu \mathrm{M}$ calcium ionophore $\mathrm{A} 23187(n=6)$ or $1 \mathrm{nM}$ angioten$\sin$ II $(n=15)$. Contraction is reversible upon removal of A23187 or angiotensin II.

\section{Discussion}

The microvasculature of the renal medulla is arranged such that blood flow to and from the outer and inner medulla follows distinct pathways. All DVR arise from efferent arterioles of juxtamedullary glomeruli and reach their destinations by first passing through outer medullary vascular bundles. DVR on the periphery of the bundles give rise to the rich capillary plexus that invests the outer medullary interbundle region of the inner stripe $(2,5)$, DVR in the center of the bundles continue to the inner medulla before terminating in capillaries. Blood returning from the inner medulla is brought into close communication with DVR as AVR from the inner medulla traverse the bundles enroute to the cortex. In contrast, AVR originating from the interbundle region of the outer medulla return to the cortex independent of the bundles. In many rodent species thin limbs of short-looped nephrons deviate to- ward (rat) or become incorporated within (psammomys) the bundles $(2,5-7)$, while collecting ducts, thick ascending limbs and the thin descending limbs of long-looped nephrons remain in the interbundle region. As pointed out by Lemley and Kriz (6), Bankir et al. (2), and others $(5,7)$, blood that perfuses nephrons in each region of the kidney returns to the cortex without the opportunity to exchange solutes and water with blood supplying the other region. It is important therefore to determine the permeability properties of vessels and tubules in each region. In this study we have obtained the first data concerning the transport characteristics of vascular segments in the outer medullary vascular bundles.

Validation of methodology. We have demonstrated the feasibility of studying the transport characteristics of microvessel segments from outer medullary vascular bundles using the in vitro method of Burg et al. (12). We also verified a dual-isotope method for simultaneously measuring sodium and urea efflux from a perfused structure (Fig. 2). We demonstrated the low permeability of the LDLu to urea $(21,26)$ (Fig. 6) as a crosscheck on the ability to perfuse microdissected medullary structures and measure urea permeability with the dual-isotope method.

Identity of microperfused $O M V R$. The next consideration to be addressed concerns the identity (DVR vs. AVR) of the microperfused OMVR. It is impossible to determine the direction of blood flow during tissue dissection. We attempted to correlate appearance with transport properties by photographing 50 perfused OMVR with differential interference contrast optics. Of the features examined (diameter, number of nuclei per unit length, wall thickness ) none proved to be predictive of transport properties, or to exhibit a bimodal distribution.

To further address this issue, we pursued three other avenues. First, many vessels were studied to determine if there is a bimodal distribution of transport properties. Second, seven randomly chosen OMVR were harvested and subjected to TEM. Those efforts led to the conclusion that all (or at least the vast majority) of microperfused OMVR are DVR. Neither sodium or urea permeability showed a bimodal distribution and all TEM specimens had a continuous endothelium, characteristic of DVR $(5,20)$. A conservative estimate of the AVR to DVR ratio in vascular bundles is $2: 1(3,33)$. Therefore, the probability of harvesting seven consecutive DVR is less than $(1 / 3)^{7}=1 / 2187$. For some unrecognized technical reason it appears to be impossible to isolate and perfuse AVR from vascular bundles in the rat, however, since all vessels were not identified by TEM we cannot state conclusively that all OMVR in Fig. 4 and Table II are DVR. Finally, vessels have been found to exhibit contraction in response to increase in intracellular calcium concentration with ionophore A23187 (Fig. 10) or angiotensin II. Contractile elements (pericytes) have been described to exist in the wall of DVR but not AVR $(5,20)$.

The SDL migrates toward the vascular bundle periphery in the inner stripe of the outer medulla of the rat. For several reasons we feel confident that OMVR and SDL have not been confused during the course of this study. First, OMVR were initially identified by the presence of RBCs in their lumens. Second, the endothelia of 7 vessels were examined by TEM. Third, none of the 102 measurements of $P_{u}$ in Tables II-V and Fig. 7 yielded a basal value for $P_{u}<200 \times 10^{-5} \mathrm{~cm} / \mathrm{s}$. In contrast, urea permeability of the SDL in hamsters was found to be only $7.4 \times 10^{-5} \mathrm{~cm} / \mathrm{s}(21)$. Finally, consecutive OMVR have contracted in response to A23187 $(n=6)$ or angiotensin II 

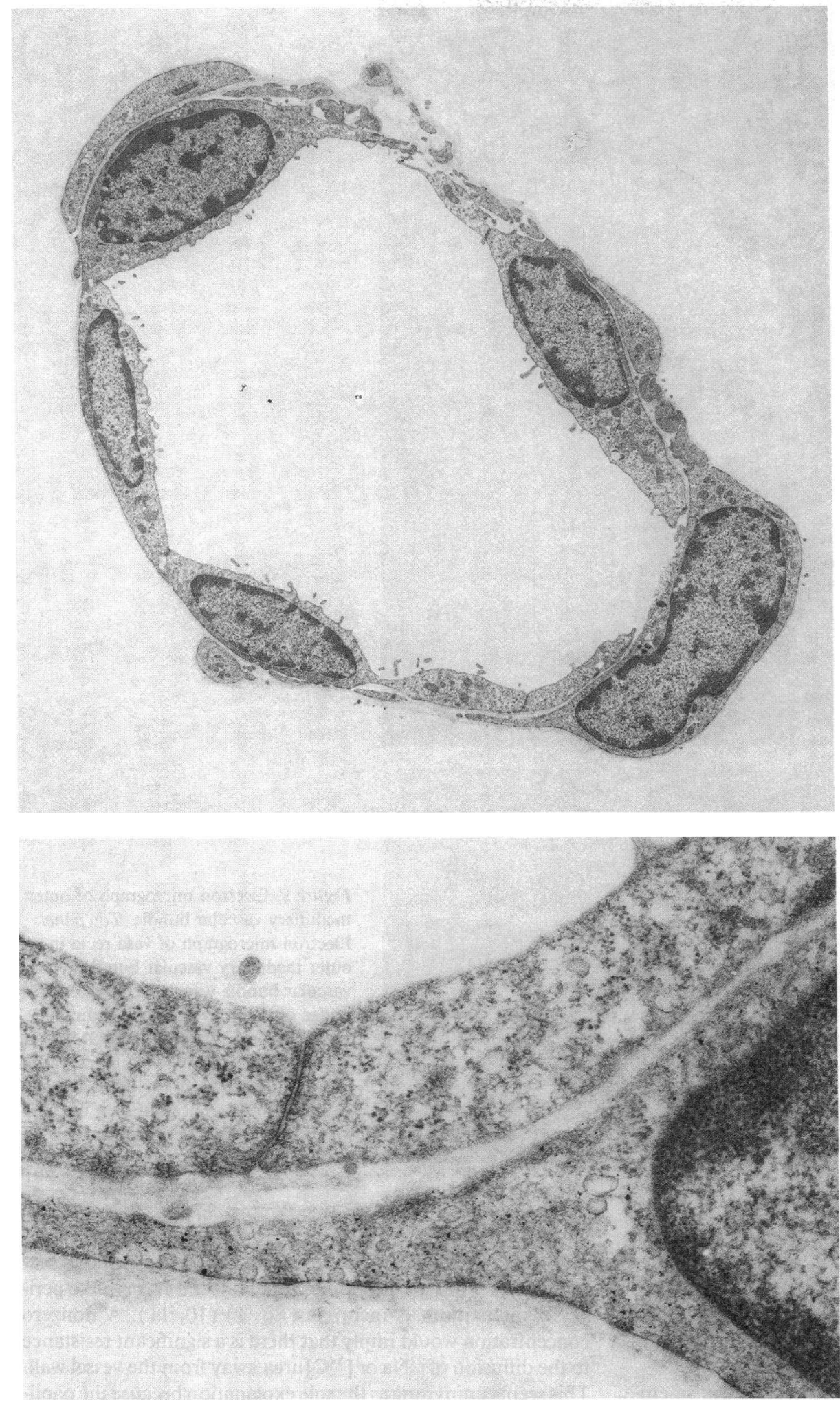

Figure 8. Electron micrograph of an OMVR. Top panel: The continuous endothelium of an OMVR $(\times 5,800)$. Bottom panel: High-power view $(\times 44,000)$ of a tight junction from the OMVR in the top panel. $(n=15)$ (Fig. 10). Nephron segments are not expected to exhibit this property.

Vasa recta sodium and urea permeabilities. $P_{\mathrm{Na}}$ and $\mathrm{P}_{\mathrm{u}}$ were measured in DVR and AVR in vivo in the inner medulla at the papillary tip (Fig. 4, Table II) based on vessel diameters of 15.6 and $20 \mu \mathrm{m}$, respectively (33). $\mathrm{P}_{\mathrm{Na}}$ does not differ significantly from that previously measured $(10,11)$. With remarkable consistency, values for $P_{u}$ were nearly identical to those for $P_{N a}$ in both vessel types. This observation could be explained by sterically unhindered diffusion of sodium and urea through a large pore paracellular pathway. In that case, in the absence of an electric field, the ratio of permeabilities is expected to be deter- 


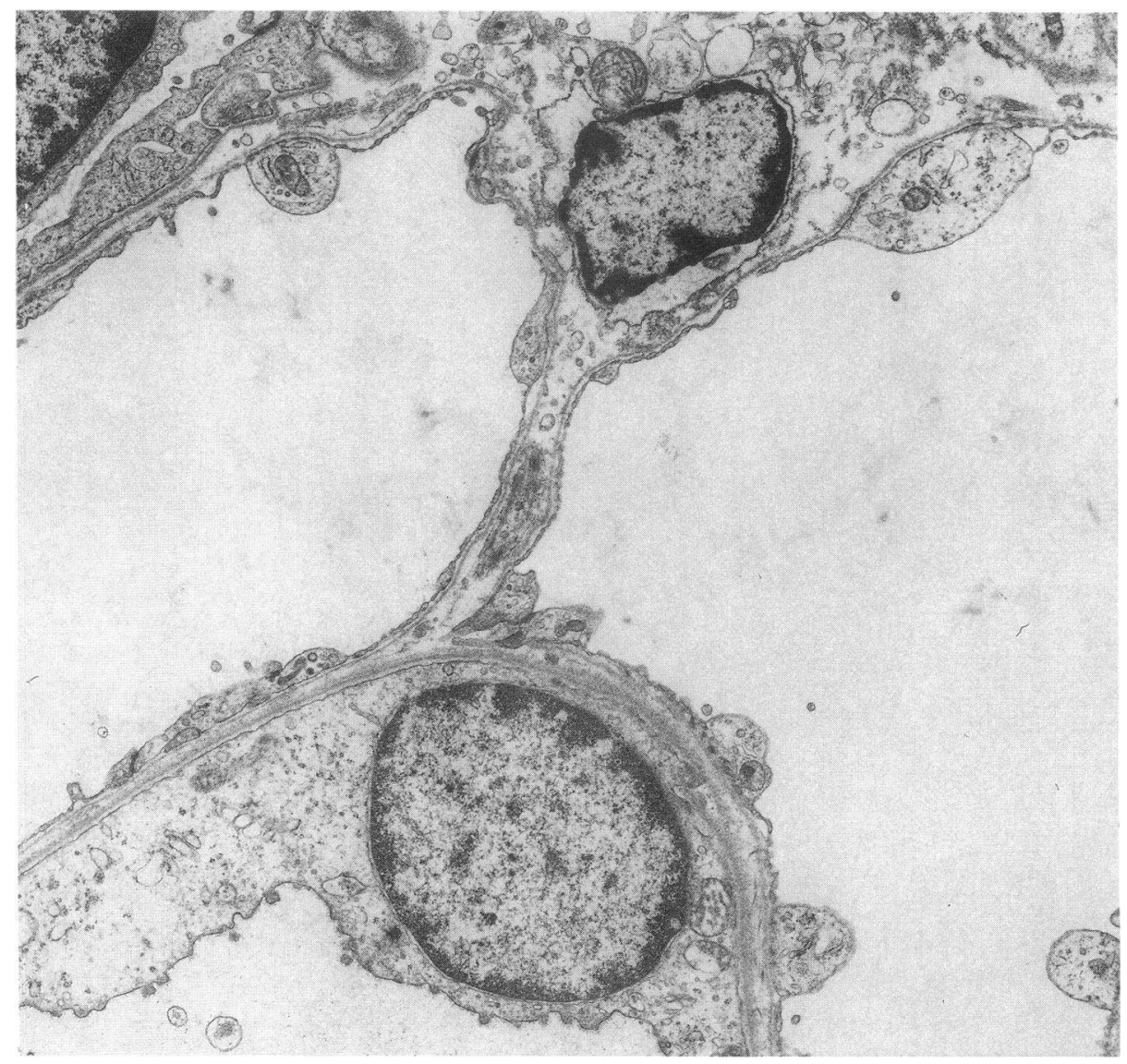

Figure 9. Electron micrograph of outer medullary vascular bundle. Top panel: Electron micrograph of vasa recta in an outer medullary vascular bundle. The vascular bundle was dissected from a wedge of tissue by the same technique used to isolate microperfused OMVR in this study. Fenestrated vessels (ascending vasa recta) are present $(\times 4600)$. Bottom panel: High-magnification view of the fenestrated ascending vasa recta wall $(\times 60,000)$.

mined by the ratio of solute diffusivity (34). The diffusivities of sodium chloride and urea are nearly identical (35). The latter suggests that the phloretin-sensitive urea transport in OMVR (Fig. 7) is unlikely to exist in the endothelia of papillary vasa recta. At present this must be taken as a hypothesis that requires experimental verification.

Eq. 1, used to calculate $P_{\mathrm{Na}}$ and $P_{u}$, neglects transmembrane volume flux. Expressions for calculating solute permeabilities which consider volume flux have been derived in the appendix of reference 11 . The values for $P_{\mathrm{Na}}$ and $P_{u}$ reported in Table II change by $5 \%$ or less when the equations in reference 11 are used to account for deviations of $\mathrm{R}_{\mathrm{Dx}}$ from unity.

Other explanations may exist for the difference in permeability properties between OMVR and papillary vasa recta. The techniques used to measure tracer efflux rates in the inner and outer medullary vessels are very different. In vivo microperfusion of papillary vessel segments may underestimate permeabilities if the assumption of zero concentration in the perivessel interstitium is incorrect (Eq. 1) $(10,11)$. A nonzero concentration would imply that there is a significant resistance to the diffusion of ${ }^{22} \mathrm{Na}$ or $\left[{ }^{14} \mathrm{C}\right]$ urea away from the vessel wall. This seems uninviting as the sole explanation because the papillary DVR and AVR permeabilities differ significantly (Table II) $(10,11)$. In contrast, in vitro microperfusion is much less likely to be subject to boundary layer effects. Another possible explanation arises from the fact that different strains of rat were used for in vivo and in vitro measurements (Munich-Wistar vs. Sprague-Dawley), which complicates the comparison of transport properties of inner and outer medullary vessels, since a strain-related difference cannot be excluded. However, given 

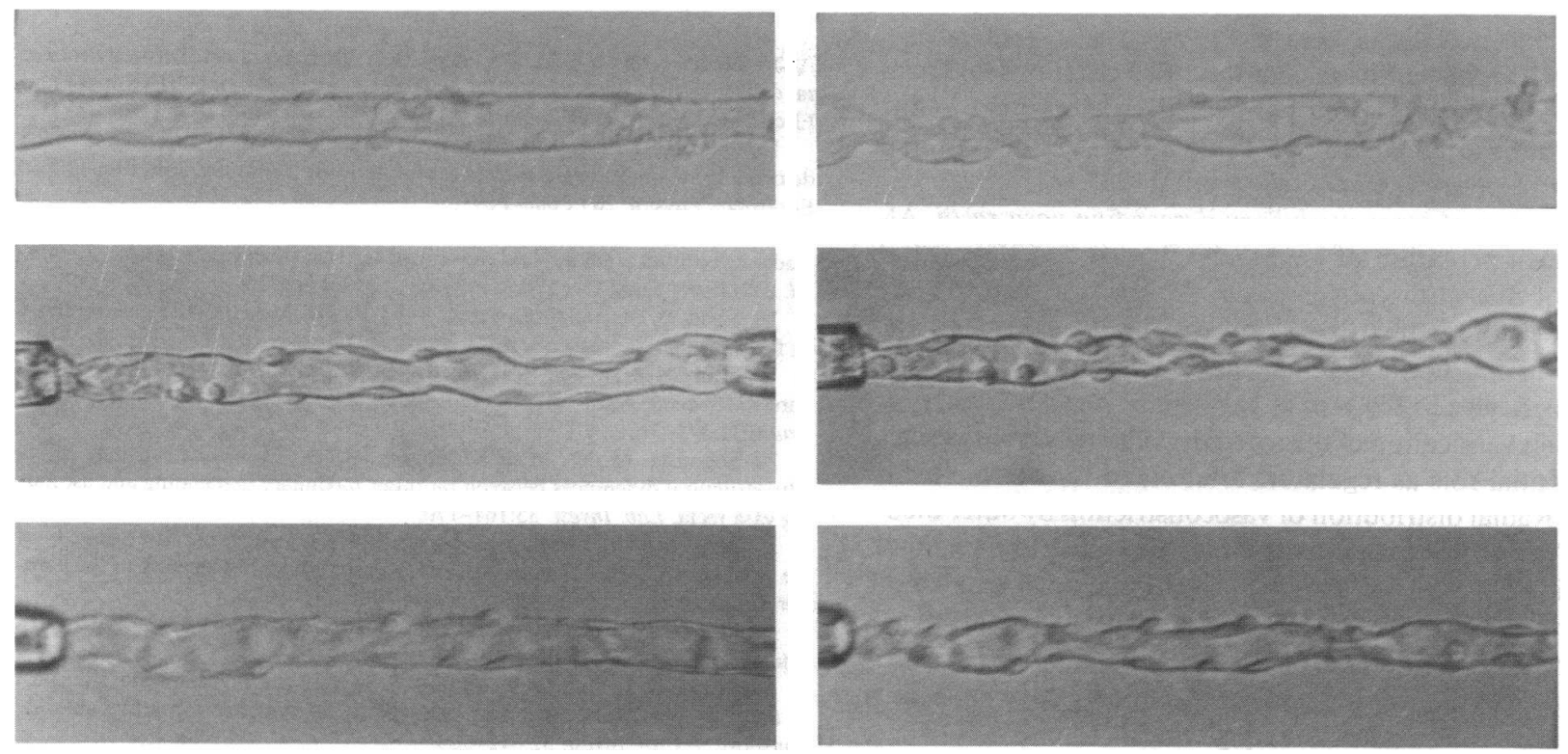

Figure 10. Constriction of OMVR by A23187 and angiotensin II. Left and right panels show the same vessel in the basal state and after vasoconstriction, respectively. The top panels show vasoconstriction with $10 \mu \mathrm{M}$ calcium ionophore, A23187, and the middle and bottom panels with $1 \mathrm{nM}$ angiotensin II.

the orders-of-magnitude difference between $P_{\mathrm{Na}}$ and $\mathrm{P}_{\mathrm{u}}$ in some OMVR segments, it seems likely that the sodium and urea transport pathways in OMVR truly differ from those in papillary vasa recta.

With regard to transport of sodium, several features deserve attention. First, some OMVR have a remarkably low $\mathrm{P}_{\mathrm{Na}}$ (Figs. 4 and 5). Second, a bimodal distribution of $\mathrm{P}_{\mathrm{Na}}$ was not found. Third, the mean value of $P_{\mathrm{Na}}$ of OMVR is similar to that of the inner medullary DVR (Table II) although the distribution of values is wider. Outer medullary DVR originate from efferent arterioles and gradually lose the wall characteristics of the parent vessel. Smooth muscle is first replaced by pericytes and then disappears (5), with the vessels destined for the inner medulla undergoing the most gradual change. It is inviting to speculate that sodium moves across OMVR exclusively by a paracellular pathway and that the lower values for $\mathrm{P}_{\mathrm{Na}}$ (Fig. 4) represent the properties of DVR centrally placed in the bundles. Those vessels are more arteriolar in nature and destined to perfuse the inner medulla (5). This implies a radial distribution of $\mathrm{P}_{\mathrm{Na}}$, increasing toward the bundle periphery. Were this correct, it would have implications for possible regional redistribution of sodium returning from the inner medulla in bundle AVR. Sodium from AVR would diffuse down the path of least resistance and thus be transported radially away from the bundle center, i.e., sodium may be transported in cascade fashion from vessel to vessel toward the bundle periphery. On the periphery of vascular bundles, a locally high concentration of sodium chloride may enhance withdrawal of water from the SDL (36). In that case, sodium might also be carried by DVR to the interbundle region providing another mechanism, aside from reabsorption of sodium from the thick ascending limb, to achieve locally high interstitial sodium concentrations. The functional implications of high sodium concentration in the interbundle region is controversial $(37,38)$ and has been reviewed by Imai and colleagues (36). Increasingly detailed consideration of local interactions (39) has characterized the evolution of theories on the urinary concentrating mechanism since the original solute mixing hypotheses were proposed $(40,41)$.

With regard to the transport of urea, the most notable feature is the very large difference between $P_{u}$ and $P_{N a}$ in the same OMVR and lack of correlation between $P_{\mathrm{Na}}$ and $P_{u}$ in these vessels (Fig. 4). Urea is transported across cells by facilitated diffusion in several tissues including red cells (31), inner medullary collecting duct $(24,32)$, and toad bladder (42). The results in Fig. 7 provide strong evidence for the existence of a similar transporter in the outer medullary DVR wall. Facilitated transport of urea probably contributes the large difference in $\mathrm{P}_{\mathrm{Na}}$ and $\mathrm{P}_{\mathrm{u}}$ in these vessels. Expression of this transporter in outer medullary DVR endothelia may have evolved to achieve high urea exchanger efficiency in the presence of a paracellular pathway which restricts movement of other small solutes (e.g., sodium). These data suggest that carrier-mediated urea transport is employed both to supply the inner medulla with urea across the wall of the inner medullary collecting duct (24) and to prevent its escape by efficient trapping in the vascular countercurrent exchanger. About $90 \%$ inhibition of $P_{u}$ occurs when $0.25 \mathrm{mM}$ phloretin is added to the bath and perfusate of the inner medullary collecting duct (24). That result contrasts with the present data which shows only $20 \%$ inhibition of $P_{u}$ in OMVR (note the scale of the ordinate in Fig. 7). Further work is required to characterize this phloretin-sensitive pathway and determine the fraction of urea transport which is accounted for by the transcellular route.

Several verifications were performed to assure that the large disparity between sodium and urea permeabilities in OMVR is not artifactual. The results in Table III demonstrate that the low apparent permeability of OMVR to sodium is not due to a lumen negative potential. Table $\mathrm{V}$ verifies that dissociation of radiolabel from $\left[{ }^{14} \mathrm{C}\right]$ urea tracer cannot explain the high OMVR urea permeability. Hepes buffer was used to perfuse and bathe OMVR in the majority of these studies. Hepes buffer was chosen over bicarbonate buffer to be consistent with prior studies $(10,11)$ and to reduce the bath flow rate without alter- 
ation of $\mathrm{pH}$ in the perfusion chamber. The latter enabled conservation of albumin. Urea permeability determined in the presence of bicarbonate buffer (Table IV) was as high as that found with Hepes (Tables II, III, and V).

Contraction of outer medullary descending vasa recta. Although documentation of vasoreactivity was not the central purpose of this study, this provides further evidence that we have properly identified the vessels perfused in this study as branches of the juxtamedullary efferent arteriole. The existence of pericytes in the wall of DVR has been described (5). The explicit verification of the reactivity of these vessels verifies their potential role as regulators total blood flow to the renal medulla. Radial distribution of vasoconstriction by outer medullary DVR in vascular bundles may also affect the regional distribution of blood flow to the inner medulla vs. outer medullary interbundle region. Since DVR are extensions of the juxtamedullary efferent arteriole, constriction of these vessels might also influence the component of the glomerular filtration which arises from juxtamedullary glomeruli.

Note added in proof. The urea transporter in the inner medullary collecting duct has been cloned. In situ hybridization has also localized the transporter to the inner stripe of the outer medulla (43).

\section{Acknowledgments}

The authors are indebted to Drs. C-L. Chou, M. Flessner, and M. Knepper for critical advice concerning the recognition of segments and perfusion of small medullary structures.

This work was supported by National Institutes of Health grant DK42495 and a grant-in-aid from the Pennsylvania affiliate of the American Heart Association. T. Pallone is an Established Investigator of the American Heart Association.

\section{References}

1. Berliner, R. W., N. G. Levinsky, D. G. Davidson, and M. Eden. 1958. Dilution and concentration of the urine and the action of antidiuretic hormone. Am. J. Med. 24:730-744.

2. Bankir, L., N. Bouby, and M.-M. Trinh-Trang-Tan. 1984. Organization of the medullary circulation: Functional implications. In Nephrology. Volume 1. R. R. Robinson, editor. Springer Verlag, Inc., New York.

3. Bankir, L., B. Kaissling, C. de Rouffignac, and W. Kriz. 1979. The vascular organization of Psammomys Obesus. Anat. Embryol. 155:149-160.

4. de Rouffignac, C., L. Bankir, and N. Roinel. 1981. Renal function and concentrating ability in a desert rodent: the Gundi (Ctenodactylus vali). Pflügers Arch. Eur. J. Physiol. 390:138-144.

5. Jamison, R. L., and W. Kriz. 1982. Urinary Concentrating Mechanism: Structure and Function. Oxford University Press, New York.

6. Lemley, K. V., and W. Kriz. 1987. Cycles and separations: the histotopography of the urinary concentrating process. Kidney Int. 31:538-548.

7. Pallone, T. L., C. R. Robertson, and R. L. Jamison. 1990. Renal medullary microcirculation. Physiol. Rev. 70:885-920.

8. Marsh, D. J., and L. A. Segel. 1971. Analysis of countercurrent diffusion exchange in blood vessels of the renal medulla. Am. J. Physiol. 221:817-828.

9. Morgan, T., and R. W. Berliner. 1968. Permeability of the loop of Henle, vasa recta, and collecting duct to water, urea and sodium. Am. J. Physiol. 215:108-115.

10. Pallone, T. L. 1991. Effect of sodium chloride gradients on water flux in rat descending vasa recta. J. Clin. Invest. 87:12-19.

11. Pallone, T. L. 1991. Transport of sodium chloride and water in rat ascending vasa recta. Am. J. Physiol. 261 (Renal Fluid Electrolyte Physiol. 30):F519F525.

12. Burg, M., J. Grantham, M. Abramow, and J. Orloff. 1966. Preparation and study of gragments of single rabbit nephrons. Am. J. Physiol. 210:1293-1298.

13. Burg, M. B. 1972. Perfusion of isolated renal tubules. Yale J. Biol. Med. 45:321-326.

14. Chou, C.-L., and M. A. Knepper. 1992. In vitro perfusion of chinchilla thin limb segments: segmentation and osmotic water permeability. Am. J. Physiol. 263(Renal Fluid Electrolyte Physiol. 32):F417-F426.
15. Flessner, M. F., S. M. Wall, and M. A. Knepper. 1991. Permeabilities of rat collecting duct segments to $\mathrm{NH}_{3}$ and $\mathrm{NH}_{4}$. Am. J. Physiol. 260(Renal Fluid Electrolyte Physiol. 29):F264-F272.

16. Pallone, T. L., J. Work, and R. L. Jamison. 1990. The resistance of the descending vasa recta to the transport of water. Am. J. Physiol. 259(Renal Fluid Electrolyte Physiol. 28):F688-F697.

17. Pallone, T. L., Y. Yagil, and R. L. Jamison. 1989. Effect of small-solute gradients on transcapillary fluid movement in renal inner medulla. Am. J. Physiol. 257(Renal Fluid Electrolyte Physiol. 26):F547-F553.

18. Good, D. W., and G. G. Vurek. 1983. Picomole quantitation of ammonia by flow-through fluorometry. Anal. Biochem. 130:199-202.

19. Ramsay, R. A., and R. H. Brown. 1955. Simplified apparatus and procedure for freezing point determination upon small volumes of fluid. J. Sci. Instrum. 32:372-375.

20. Schwartz, M. M., M. J. Karnovsky, and M. A. Venkatachalam. 1976. Ultrastructural differences between rat inner medullary descending and ascending vasa recta. Lab. Invest. 35:161-170.

21. Imai, M., M. Hayashi, and M. Araki. 1984. Functional heterogeneity of the descending limbs of Henle's loop I. Internephron heterogeneity in the hamster kidney. Pflügers Arch. Eur. J. Physiol. 402:385-392.

22. Burg, M. B., and N. Green. 1973. Function of the thick ascending limb of Henle's loop. Am. J. Physiol. 224:659-668.

23. Rocha, A. S., and J. P. Kokko. 1973. Sodium chloride and water transport in the medullary thick ascending limb of Henle: evidence for active chloride transport. J. Clin. Invest. 52:612-623.

24. Chou, C-L., and M. A. Knepper. 1989. Inhibition of urea transport in inner medullary collecting duct by phloretin and urea analogues. Am. J. Physiol. 257(Renal Fluid Electrolyte Physiol. 26):F359-F365.

25. Sands, J. M., and M. A. Knepper. 1987. Urea permeability of mammalian inner medullary collecting duct system and papillary surface epithelium. J. Clin. Invest. 79:138-147.

26. Imai, M., J. Taniguchi, and K. Yoshitomi. 1988. Transition of permeability properties along the descending limb of long-looped nephron. Am. J. Physiol. 254(Renal Fluid Electrolyte Physiol. 23):F323-F328.

27. Chou, C.-L., and M. Knepper. 1993. In vitro perfusion of chinchilla thin limb segments: urea and $\mathrm{NaCl}$ permeabilities. Am. J. Physiol. 264(Renal Fluid Electrolyte Physiol. 33):F337-F343.

28. Imai, M. 1977. Function of the thin ascending limb of Henle of rats and hamsters perfused in vitro. Am. J. Physiol. 232(Renal Fluid Electrolyte Physiol. 3):F201-F209.

29. Imai, M. 1984. Functional heterogeneity of the descending limbs of Henle's loop II. Interspecies differences among rabbits, rats, and hamsters. Pflügers Arch. Eur. J. Physiol. 402:393-401.

30. Imai, M., and E. Kusano. 1982. Effects of arginine vasopressin on the thin ascending limb of Henle's loop in hamsters. Am. J. Physiol. 243(Renal Fluid Electrolyte Physiol. 12):F167-F172.

31. Brahm, J. 1983. Urea permeability of human red cells. J. Gen. Physiol. 82:1-23.

32. Kondo, Y., and M. Imai. 1987. Effects of glutaraldehyde fixation on renal tubular function I. Preservation of vasopressin-stimulated water and urea pathways in rat papillary collecting duct. Pflügers Arch. Eur. J. Physiol. 408:479-483.

33. Holliger, C., K. V. Lemley, S. L. Schmitt, F. C. Thomas, C. R. Robertson, and R. L. Jamison. 1983. Direct determination of vasa recta blood flow in the rat renal papilla. Circ. Res. 53:401-413.

34. Bull, H. B. 1971. An Introduction to Physical Biochemistry. Edition 2. F. A. Davis Co., Philadelphia. 291.

35. Andrioli, T. E., editor. Physiology of Membrane Disorders. 1986. 2nd Edition. Plenum Publishing Corp., New York. 112.

36. Imai, M., J. Taniguchi, and K. Tabei. 1987. Function of thin loops of Henle. Kidney Int. 31:565-579.

37. Bonventre, J. V., and C. Lechene. 1980. Renal medullary concentrating process: an integrative hypothesis. Am. J. Physiol. 239(Renal Fluid Electrolyte Physiol. 8):F578-F588.

38. Taniguchi, J., K. Tabei, and M. Imai. 1987. Profiles of water and solute transport along long-loop descending limb: analysis by mathematical model. $\mathrm{Am}$. J. Physiol. 252(Renal Fluid Electrolyte Physiol. 21):F393-F402.

39. Wexler, A. S., R. E. Kalaba, and D. J. Marsh. 1991. Three-dimensional anatomy and renal concentrating mechanism. I. Modeling results. Am. J. Physiol. 260 (Renal Fluid Electrolyte Physiol. 29):F368-F383.

40. Stephenson, J. L. 1972. Concentration of urine in a central core model of the renal counterflow system. Kidney Int. 2:85-94.

41. Kokko, J. P., and F. C. Rector Jr. 1972. Countercurrent multiplication system without active transport in inner medulla. Kidney Int. 2:214-223.

42. Levine, S., N. Franki, and R. M. Hays. 1973. A saturable, vasopressin-sensitive carrier for urea and acetamide in the toad bladder epithelial cell. J. Clin. Invest. 52:2083-2086.

43. You, G., C. P. Smith, Y. Kanai, W.-S. Lee, M. Stelzner, and M. A. Hediger. 1993. Cloning and characterization of the vasopressin-regulated urea transporter. Nature (Lond.). 365:845-847. 